\title{
Peptide-based synthetic pulmonary surfactant for the treatment of respiratory distress disorders
}

Otonye Braide-Moncoeur ${ }^{1, *}$, Nhi T. Tran ${ }^{1}$, Joanna R. Long ${ }^{2}$

1. Department of Chemistry, College of Liberal Arts and Sciences, University of Florida, Gainesville, FL 32610 USA

2. Department of Biochemistry and Molecular Biology, College of Medicine, University of Florida, Gainesville, FL 32610 USA

* Present address: Department of Chemistry, Gordon College, 255 Grapevine Road, Wenham, MA 01984 USA

Corresponding author:

Joanna R. Long

irlong@ufl.edu

352-846-1506

Other author email addresses:

Otonye Braide-Moncoeur

otonye.braide@gordon.edu

Nhi T. Tran

nhittran@ufl.edu

\section{Abstract}

$\mathrm{KL}_{4}$ (Sinapultide) represents the first peptide-based replacement for surfactant protein B in pulmonary surfactant (PS) therapies approved for clinical use. Surfaxin, its formulation with PS lipids, shows the promise of synthetic PS for replacing animal-derived PS in the treatment of respiratory distress syndromes and for treating acute lung injury. Efforts to characterize the molecular basis for $\mathrm{KL}_{4}$ function have revealed the peptide exhibits a helical structure which differentially partitions in response to both lipid saturation levels and $\mathrm{pH}$. The penta-residue repeat of $\mathrm{KL}_{4}$ leads to adaptive peptide helicity, varying with partitioning depth, and suggests structural plasticity may represent an important mechanism for differential trafficking of lipids, particularly in intra-alveolar surfactant for the formation of stable DPPC monolayers at air-water interfaces.

\section{Graphical abstract}

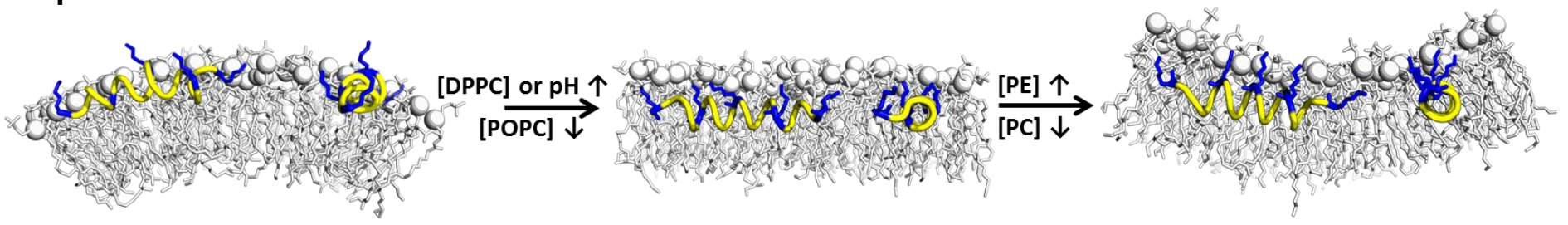


Pulmonary surfactant, surfactant protein $B$ and respiratory distress

Pulmonary surfactant (PS) is a lipid-rich fluid which forms the inner lining of the alveoli; its primary functions are to minimize surface tension at the alveolar air-fluid interface and to provide a barrier against disease [1-6]. Inadequate levels of PS or breakdown of PS causes respiratory distress syndromes (RDS). PS is produced in alveolar epithelial type II (AE2) cells (Figure 1A) and secreted into the alveolar space as multilamellar vesicles. Extracellular surfactant serves as a reservoir for lipids which are cycled to a monolayer at the air-water interface; PS lipid reserves are turned over every 5-10 hours [7]. The phospholipid composition of PS is unusual with much higher levels of DPPC and PG than typically observed in cellular lipid bilayers. DPPC, a fully saturated lipid, can withstand high lateral surface pressures and lowers surface tension at the air-water interface [8]. Equally critical to the function of PS is surfactant protein B (SP-B), a lipophilic protein essential for the packaging of intracellular PS as lamellar bodies which convert to tubular myelin on secretion and form the multilayer surface film observed at the air-water interface (Figure 1B). It is thought that DPPC may be specifically enriched at the air-water interface by trafficking and sorting of lipids in bulk PS by SP-B. Insufficient PS levels are a leading cause of RDS and death in premature infants, with infants born at 26-28 weeks gestation having a $50 \%$ incidence of RDS and at 30-31 weeks gestation a $25 \%$ incidence. SP-B mutations or deletions lead to disorganization of lamellar bodies, an abnormal morphology for alveolar type II cells, and loss of tubular myelin organization preventing proper lung function and viability [9-13].

Figure 1. Transmission electron micrographs of $A)$ a human lung AE2 cell displaying typical lamellar bodies ( $\mathrm{Lb}$ ) and nucleus (Nu); and B) intra-alveolar PS from a rat lung displaying the typical lattice-like appearance of tubular myelin which is in close contact with the alveolar lining layer (arrowheads). Vesicular surfactant (small arrows) is seen near the apical surface of the alveolar epithelium. Figures reproduced with permission from $\mathrm{H}$. Fehrenbach, Respiratory Research (2001) 2:33-46 [2].

The clinical introduction of bovine and porcine PS extracts to treat premature infants in the early 1990s revolutionized the treatment of RDS [14-16]. Although

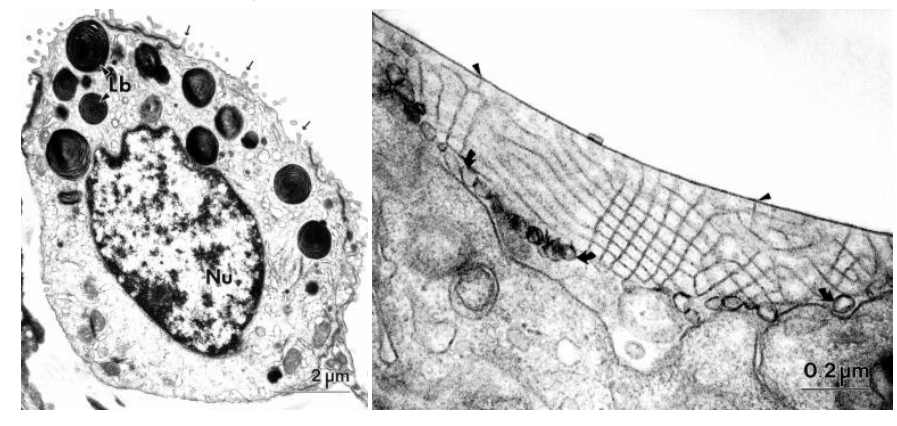
xenogeneic PS is expensive and raises concerns regarding purity, immunogenicity, and uniformity, the high hydrophobicity of SP-B has made heterologous expression and purification of sufficient protein for clinical PS therapies untenable [17]. Thus, until recently, treatment of RDS in premature infants has continued to rely primarily on administration of saline suspensions of PS from animal sources.

\section{Identification and development of PS peptides for treatment of RDS}

Characterization of the functional properties of SP-B resulted in identification of fragments of the native sequence which retain these functions, particularly peptides corresponding to the $\mathrm{N}$ - and $\mathrm{C}$-termini. The $\mathrm{N}$ terminal 25-amino acid segment of SP-B, SP-B ${ }_{1-25}$, is surface active [18], and has been shown to interact with specific anionic lipids to facilitate squeeze-out of lipids [19-21]. The C-terminal segment of SP-B, SP-B ${ }_{59-80}$, has shown efficacy in in vitro assays measuring surface tension [22]. Synthetic, peptide-based SP-B replacements can remove the immunologic risks associated with animal-derived surfactant and potentially allow for greater therapeutic consistency. The possibility also exists for tailoring specific PS formulations to different respiratory diseases. Of particular clinical interest, the charge distribution of the last 22 amino acids of SP-B served as the template for designing the $\mathrm{KL}_{4}$ peptide [23], known clinically as sinapultide. To date, $\mathrm{KL}_{4}$ has enjoyed the most clinical success as a synthetic peptide replacement for SP-B, discussed below, including approval by the US Food and Drug Administration in 2012 for prevention of RDS in at-risk premature infants.

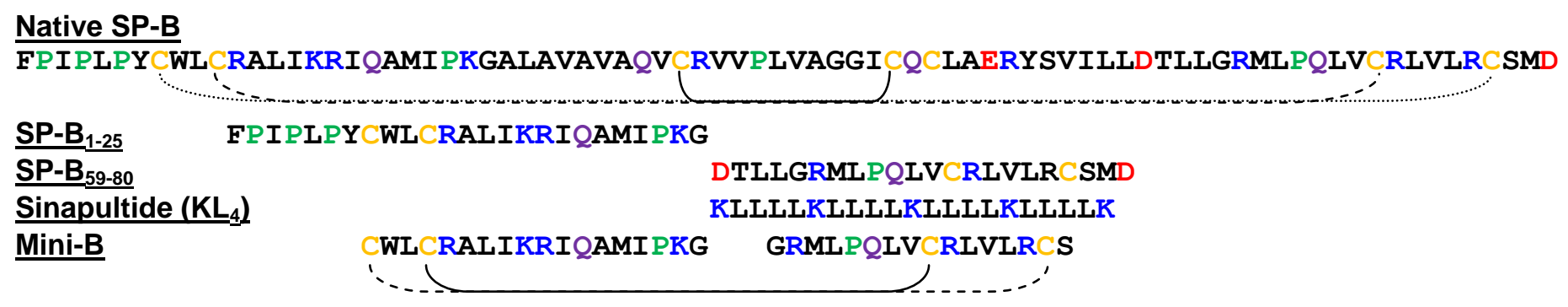

Figure 2. SP-B and fragments of SP-B important to function with charged amino acids (blue cationic/red anionic), polar amino acids (purple), cysteines (yellow orange), and prolines (green) highlighted. Brackets indicate disulfide bonds. The functional peptide mimic of SP-B ${ }_{59-80}$, known as Sinapultide or $\mathrm{KL}_{4}$, utilized in Surfaxin is also shown. 
Development of sinapultide, early studies of efficacy, and preclinical studies

Cochrane and co-workers pursued functional studies of peptide variants based on the SP-B C-terminus, SP$\mathrm{B}_{59-80}$, after establishing that the hydrophilic residues were necessary for its function. They made simplified versions in which charged and polar amino acids were uniformly converted to either arginine, lysine, or aspartic acid while hydrophobic amino acids were converted to leucines. Cationic peptides, termed $\mathrm{RL}_{4}$ and $\mathrm{KL}_{4}$, had similar activity to the original peptide while the anionic peptide, $\mathrm{DL}_{4}$, was much less active [23]. Measurements with varying combinations of zwitterionic and anionic phospholipids led to the conclusion that the cationic amino acids could better interact with both $P C$ and $P G$ lipids giving $\mathrm{RL}_{4}$ and $\mathrm{KL}_{4}$ superior surface properties relative to $\mathrm{DL}_{4}$ [23-25]. The lysine variant, later named sinapultide [26] and patented in 1995 [27], was ultimately selected for preclinical and clinical studies; in order to form active PS the peptide is combined with DPPC, POPG, and palmitic acid to form a suspension of peptide-containing liposomes in buffered saline. An initial study utilizing preterm infant rhesus monkeys showed efficacy for $\mathrm{KL}_{4}$-surfactant which was superior to Exosurf, a non-peptide-containing synthetic surfactant [28]. An initial test of safety and efficacy for $\mathrm{KL}_{4^{-}}$ surfactant in 47 premature human infants showed strong efficacy with only two enrolled participants requiring crossover to a previously FDA-approved surfactant (either Survanta or Exosurf) during the study [29].

Further pre-clinical studies showed success in treatment of meconium aspiration syndrome (MAS) in adult rabbits and newborn rhesus monkeys following intratracheal instillation of human meconium to induce pulmonary injury [30], and that $\mathrm{KL}_{4}$-surfactant exhibited an efficacy similar to porcine-derived surfactant in treating preterm lambs with severe RDS [31]. Several more recent studies indicate further improvements in methods of delivery may enhance the use and efficacy of $\mathrm{KL}_{4}$-based therapies, enabling them to supplant animal-based surfactants as the clinical standard of care for RDS [32-36].

Sinapultide formulation and clinical development

$\mathrm{KL}_{4}$, or sinapultide, is made synthetically and the purified peptide is combined with DPPC and POPG phospholipids and palmitic acid in a buffered saline suspension. This formulation, known as lucinactant and marketed by Discovery Laboratories, Inc., as Surfaxin, is administered intratracheally whereupon it spontaneously enters the alveoli and lowers surface tension, reducing the need for mechanical ventilation; it has shown efficacy in treating several respiratory conditions. While under development, lucinactant was designated as an Orphan Drug Product by the US FDA for the treatment or prevention of RDS in premature infants [37, 38], the prevention of bronchopulmonary dysplasia in premature infants [39], the treatment of meconium aspiration syndrome in newborn infants [40], and the treatment of acute respiratory distress syndrome in adults [41]. The necessity of developing a formulation containing phospholipids, in addition to the unusually high melting temperature of DPPC, led to unique challenges in developing a manufacturing process and clinical protocols sufficiently robust for FDA approval. It received authorization for clinical use in treating infant RDS in 2012 [42]. A lyophilized form of Surfaxin as well as an aerosolized version, known as Aerosurf, are currently in clinical trials for the treatment of RDS. An aerosol form is also in early development for the treatment of viral- or chemically-induced acute lung injury (ALI) [43]. The properties of lucinactant suggest it might have use in drug delivery applications in addition to the treatment of RDS and ALI [44]. Given the recent approval of lucinactant, large-scale clinical studies comparing its efficacy to animal-derived PS are still lacking and of significant interest to the pulmonology community $[45,46]$, particularly since in vitro studies suggest it might be more resistant to inactivation by oxidation or serum proteins $[47,48]$.

\section{In vitro mechanistic studies of PS formulations}

SP-B in native PS functions at a concentration of $\sim 400-800$ lipids per SP-B monomer; Surfaxin contains a molar ratio of lipids/sinapultide of $>100: 1$. A primary focus in early PS research was the functional properties of SP-B and synthetic peptides in lipid monolayers at air-water interfaces. Their ability to facilitate, at low peptide/protein concentrations, the formation of stable lipid monolayers which can withstand much higher lateral pressures than monolayers of pure DPPC or lipid mixtures remains a hallmark of peptides targeted for PS-based therapies. Their biophysical properties preclude characterizing them under functional conditions by standard structural biology techniques, such as X-ray crystallography or solution NMR. Based on circular dichroism measurements, FTIR studies, and molecular modelling, SP-B is thought to form amphiphilic helices linking lipid mono- and bilayer interfaces to regulate their physical properties and lipid trafficking [49-51]. Partitioning and folding of amphiphilic peptide helices at membrane interfaces is a well-recognized motif in structural biology; amphiphilic helices play key roles in protein and membrane regulation, including gating of ion channels and activation of G-protein coupled receptors. Simple examples have primary sequences of periodically spaced hydrophobic and hydrophilic residues that are easily segregated on the faces of an $\alpha$-helix 
by assuming a canonical 3.6 residues/turn and $i \rightarrow i+4$ hydrogen bonding. $\mathrm{KL}_{4}$ has also been shown by $C D$ and FTIR measurements to be primarily helical in a lipid environment [52-55]. However, the periodicity of cationic lysines in $\mathrm{KL}_{4}$ rules out a structural model in which the peptide binds to lipid interfaces as a classic, amphiphilic $\alpha$-helix (Figure 3a), and its sequence is intermediate in hydrophobicity (24\% charged/polar residues) relative to typical amphiphilic $\alpha$-helices ( $50 \%$ charged/polar residues), such as antimicrobial peptides, and fully hydrophobic transmembrane $\alpha$-helices, which are important in cellular regulation. Low resolution studies attempting to qualitatively determine the structure and orientation of $\mathrm{KL}_{4}$ in lipid environments have yielded conflicting interpretations regarding the secondary structure of $\mathrm{KL}_{4}$ as well as its orientation in a lipid environment [52, 53, 56, 57]. Some of this divergence between studies is due to differences in sample preparation, lipids utilized, and experimental configuration, as CD spectra as a function of negatively charged lipids clearly show [58].
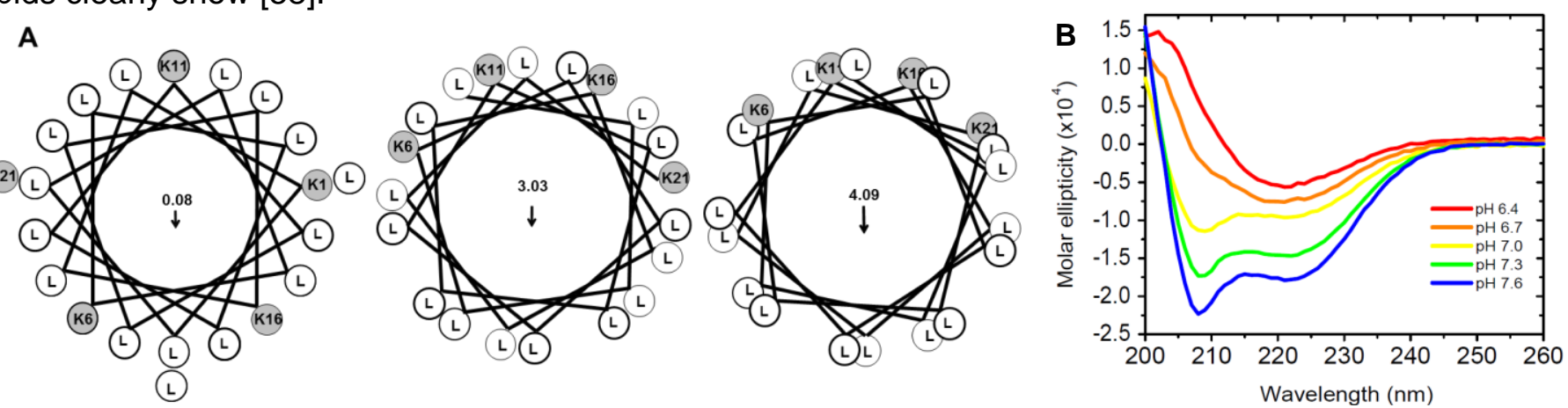

Figure 3. A) Helical wheel plots for $\mathrm{KL}_{4}$ with varying pitch. Wheels generated assuming a canonical $\alpha$-helix (left); using the average torsion angles determined in POPC/POPG vesicles, $\mathrm{pH} 7.4$ (middle; 4.1 residues/turn) [54]; and using the average torsion angles suggested by preliminary NMR experiments with DPPC/POPG vesicles, $\mathrm{pH} 7.4$ (right; 4.6 residues/turn). Arrows indicate the net hydrophobic moments resulting from the distribution of charged lysine sidechains on the helix surface. The first lysine is omitted in NMR-based models as data indicate the N-terminus is less structured relative to the rest of the peptide. B) CD spectra of $\mathrm{KL}_{4}$ in POPC:POPG lipid vesicles as a function of buffer $\mathrm{pH}$. $\mathrm{KL} \mathrm{L}_{4} \mathrm{Structure}$ in $\mathrm{DPPC}: \mathrm{POPC}$ lipid vesicles also exhibits a pH dependence. The $\mathrm{pH}$ shifts from 7.3 to 6.8 on secretion from type II pneumocytes into the extracellular PS reservoir [59, 60].

Research in my group has focused on characterizing the molecular mechanisms of lipid dynamics and interactions with $\mathrm{KL}_{4}$ to provide guidance for the development of next generation synthetic PS therapies. To examine both the peptide and its effects on PS lipids at clinically relevant concentrations in lipid environments mimicking native PS and lucinactant, we have developed and applied solid state NMR and EPR spectroscopic techniques. This enables a systematic approach to understanding the relationship between peptide partitioning and structure as a function of lipid environment and to measuring peptide-mediated changes in lipid dynamics to discern its effects on specific lipid species, particularly DPPC. Initially, we characterized the structure of $\mathrm{KL}_{4}$ in a model lipid system containing monounsaturated POPC and POPG and found that it forms a helical structure with torsion angles at the sites of measurement that deviate significantly from a classic $\alpha$-helix [54]. A comparison of its effects on DPPC/POPG vs. POPC/POPG lipid vesicles indicate the binding of $\mathrm{KL}_{4}$ is dependent on the level of mono-unsaturation in the fatty acid chains, with $\mathrm{KL}_{4}$ partitioning more peripherally in a fully mono-unsaturated lipid environment and more deeply inserting into a DPPC-rich environment [55]. Addition of $\mathrm{KL}_{4}$ increases collective motions in POPC/POPG lipid bilayers and decreases collective motions in DPPC/POPG lipid bilayers while attenuating local lipid dynamics in both environments, consistent with different peptide partitioning depths between the two lipid bilayer systems [61]. These observations suggest that the addition of $\mathrm{KL}_{4}$ leads to positive curvature strain in the POPC/POPG lipid system but stabilizes the DPPC/POPG lipid bilayers. Near the phase transition temperature of the DPPC/POPG lipid mixtures, which is just below the physiologic temperature of lung surfactant, $\mathrm{KL}_{4}$ causes phase separation with the DPPC remaining in a gel phase and the POPG partitioned between gel and fluid phases. The partitioning and orientation of $\mathrm{KL}_{4}$ in DPPC/POPG and POPC/POPG phospholipid bilayers, as inferred from the leucine side chain dynamics and EPR power saturation measurements for spin-labeled variants of $\mathrm{KL}_{4}$, is consistent with monomeric $\mathrm{KL}_{4}$ lying in the plane of the bilayers and adopting an adaptive helical structure which confers amphiphilicity and allows partitioning into the lipid hydrophobic interior $[61,62]$. The structural plasticity of $\mathrm{KL}_{4}$ and its adaptive behavior in differentially partitioning into lipid lamellae containing varying levels of saturation, leading to subsequent changes in curvature strain, suggest a mechanism for its role in restoring lung compliance in which it differentially traffics DPPC to form a stable monolayer at the air-water interface (Figure 4). More recently we have observed, via CD measurements, its helical structure is $\mathrm{pH}$ dependent over the $\mathrm{pH}$ range experienced by PS on secretion from type II pneumocytes into the extracellular space (Figure 3b) [59, 60]. This observation suggests peptide partitioning into the hydrophobic lipid bilayer interior shifts the $\mathrm{pK}_{\mathrm{a}}$ values of charged moieties within $\mathrm{KL}_{4}$ to a physiologically relevant regime, with changes in $\mathrm{pH}$ also affecting 
peptide partitioning depth and lipid curvature strain. If a similar phenomenon exists with SP-B, it would provide an explanation for the lipid morphology changes observed during PS secretion and re-uptake, warranting a more thorough investigation of peptide/protein partitioning and structure with respect to $\mathrm{pH}$ to direct further development of synthetic replacements.

Figure 4. $\mathrm{KL}_{4}$ Models built using backbone torsion angle restraints from ssNMR measurements. (A) $\mathrm{A} \mathrm{KL}_{4}$ conformer from measurements with POPC-rich samples; (B) a second conformer from measurements with DPPC-rich samples. Models created using PyMol [63] and Membrane Builder [64]

\section{Other PS active peptides and future directions}

While $\mathrm{KL}_{4}$ was developed based on the hydrophilic/ hydrophobic pattern in SP-B ${ }_{59-80}$, their primary sequences have only modest similarity raising the question of whether $\mathrm{KL}_{4}$ and $S P-B_{59-80}$ are comparable in their function in a lipid environment. NMR and CD studies indicate SP-B ${ }_{59-80}$ exhibits structural plasticity which is lipid dependent and has similar effects on PS lipid dynamics [65]. However, SP$\mathrm{B}_{59-80}$ contains a proline residue in the middle of the sequence leading to a helix-turn-helix structure in

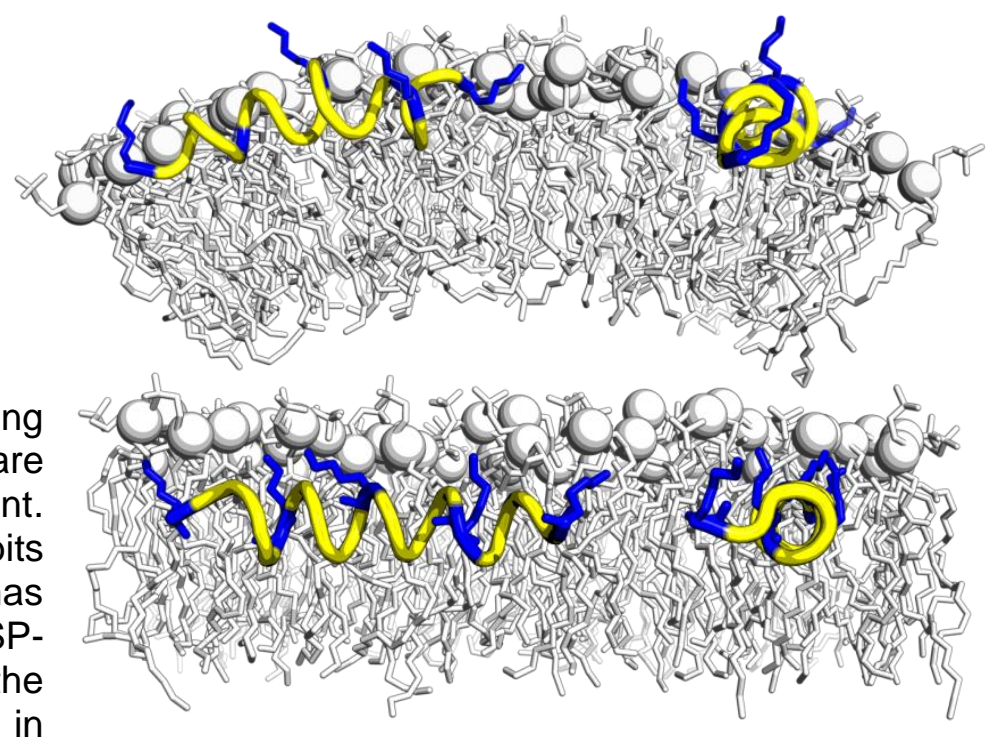
which the turn structure changes with environment, suggesting that while its function may be similar to $\mathrm{KL}_{4}$ its mechanism of action may be quite different [66]. SP-B ${ }_{1-25}$, which also exhibits functional activity, does not exhibit structural adaptation to different lipid environments. However, its effects on lipid dynamics, including the induction of non-lamellar lipid polymorphisms, differ markedly from SP-B $\mathrm{B}_{59-80}$ and $\mathrm{KL}_{4}$, and it also specifically affects DPPC dynamics in PS lipid mixtures $[67,68]$. SP-B ${ }_{1-25}$ also differs from SP-B $\mathrm{B}_{8-25}$ in its ability to alter lipid morphology, suggesting that the $\mathrm{N}$-terminal, proline-rich segment is critical to how the amphiphilic helix encompassing residues 9 through 25 partitions into the membrane and influences lipid organization. A hybrid peptide, termed Mini-B which contains SP-B residues 8-25 and 63-78 and disulfide bridges similar to the native protein, has been demonstrated to have in vitro activity similar to full SP-B [69, 70]. It is considerably more active in its oxidized form, and it out-performs a physical mixture of $\mathrm{N}$-terminal and $\mathrm{C}$-terminal peptides. These observations suggest the $\mathrm{N}$ - and $\mathrm{C}$-termini of SP-B play complimentary roles in lipid organization and trafficking, and that future research developing chimeric constructs of SP-B ${ }_{1-25}$ combined with either SP-B ${ }_{59-80}$ or $\mathrm{KL}_{4}$ variants for clinical use is merited.

\section{ACKNOWLEDGEMENTS}

We would like to thank Drs. Anil Mehta, Gail Fanucci, Yilin Meng and Adrian Roitberg for helpful discussions. JRL acknowledges support from the National Science Foundation Cooperative Agreement No. DMR-1157490.

\section{REFERENCES}

1. Goerke, J. (1998). Pulmonary surfactant: functions and molecular composition. Bba-Mol Basis Dis 1408, 79-89.

2. Fehrenbach, H. (2001). Alveolar epithelial type II cell: defender of the alveolus revisited. Respir Res 2, 33-46.

3. Piknova, B., Schram, V., and Hall, S.B. (2002). Pulmonary surfactant: phase behavior and function. Curr Opin Struct Biol 12, 487-494.

4. Whitsett, J.A., and Weaver, T.E. (2002). Mechanisms of disease: Hydrophobic surfactant proteins in lung function and disease. New Engl J Med 347, 2141-2148.

5. Wright, J.R. (2005). Immunoregulatory functions of surfactant proteins. Nat Rev Immunol 5, 58-68.

6. Serrano, A.G., and Perez-Gil, J. (2006). Protein-lipid interactions and surface activity in the pulmonary surfactant system. Chem Phys Lipids 141, 105-118.

7. Wright, J.R., and Clements, J.A. (1987). Metabolism and Turnover of Lung Surfactant. Am Rev Respir Dis 136, 426-444.

8. Veldhuizen, R., Nag, K., Orgeig, S., and Possmayer, F. (1998). The role of lipids in pulmonary surfactant. Bba-Mol Basis Dis 1408, 90-108. 
9. Ballard, P.L., Nogee, L.M., Beers, M.F., Ballard, R.A., Planer, B.C., Polk, L., deMello, D.E., Moxley, M.A., and Longmore, W.J. (1995). Partial deficiency of surfactant protein B in an infant with chronic lung disease. Pediatrics 96, 1046-1052.

10. Clark, J.C., Wert, S.E., Bachurski, C.J., Stahlman, M.T., Stripp, B.R., Weaver, T.E., and Whitsett, J.A. (1995). Targeted Disruption of the Surfactant Protein-B Gene Disrupts Surfactant Homeostasis,

Causing Respiratory-Failure in Newborn Mice. P Natl Acad Sci USA 92, 7794-7798.

*Seminal paper demonstrating the critical role of SP-B in PS trafficking and activity

11. Clements, J.A., and Avery, M.E. (1998). Lung surfactant and neonatal respiratory distress syndrome. Am J Respir Crit Care Med 157, S59-66.

12. Weaver, T.E., and Conkright, J.J. (2001). Functions of surfactant proteins B and C. Annu Rev Physiol 63, 555-578.

13. Hawgood, S., Derrick, M., and Poulain, F. (1998). Structure and properties of surfactant protein B. Biochim Biophys Acta 1408, 150-160.

14. Revak, S.D., Merritt, T.A., Degryse, E., Stefani, L., Courtney, M., Hallman, M., and Cochrane, C.G. (1988). Use of Human Surfactant Low-Molecular Weight Apoproteins in the Reconstitution of Surfactant Biologic Activity. J Clin Invest 81, 826-833.

15. Robertson, B., and Halliday, H.L. (1998). Principles of surfactant replacement. Bba-Mol Basis Dis 1408, 346-361.

16. Ghodrat, M. (2006). Lung surfactants. Am J Health Syst Pharm 63, 1504-1521.

17. Serrano, A.G., Cabre, E.J., Oviedo, J.M., Cruz, A., Gonzalez, B., Palacios, A., Estrada, P., and PerezGil, J. (2006). Production in Escherichia coli of a recombinant C-terminal truncated precursor of surfactant protein B (rproSP-B-Delta c). Structure and interaction with lipid interfaces. BbaBiomembranes 1758, 1621-1632.

18. Waring, A., Taeusch, W., Bruni, R., Amirkhanian, J., Fan, B., Stevens, R., and Young, J. (1989). Synthetic amphipathic sequences of surfactant protein-B mimic several physicochemical and in vivo properties of native pulmonary surfactant proteins. Peptide research 2, 308-313.

*One of two key studies showing 20-25 amino acid fragments of SP-B retain much of its activity

19. Bruni, R., Taeusch, H.W., and Waring, A.J. (1991). Surfactant Protein-B - Lipid Interactions of Synthetic Peptides Representing the Amino-Terminal Amphipathic Domain. P Natl Acad Sci USA 88, 7451-7455.

${ }^{*} \mathrm{~A}$ followup paper demonstrating the activity of the N-terminus of SP-B

20. Longo, M.L., Bisagno, A.M., Zasadzinski, J.A.N., Bruni, R., and Waring, A.J. (1993). A Function of Lung Surfactant Protein Sp-B. Science 261, 453-456.

21. Lee, K.Y.C., Lipp, M.M., Zasadzinski, J.A., and Waring, A.J. (1997). Effects of lung surfactant specific protein SP-B and model SP-B peptide on lipid monolayers at the air-water interface. Colloid Surface A 128, 225-242.

22. Revak, S.D., Merritt, T.A., Hallman, M., Heldt, G., Lapolla, R.J., Hoey, K., Houghten, R.A., and Cochrane, C.G. (1991). The Use of Synthetic Peptides in the Formation of Biophysically and Biologically-Active Pulmonary Surfactants. Pediatr Res 29, 460-465.

${ }^{*}$ The second key study showing 20-25 amino acid fracgments of SP-B retain much of its activity

23. Cochrane, C.G., and Revak, S.D. (1991). Pulmonary Surfactant Protein-B (Sp-B) - Structure-FunctionRelationships. Science 254, 566-568.

${ }^{*}$ Seminal paper describing the development of $\mathrm{KL}_{4}$ or sinapultide

24. Vincent, J.S., Revak, S.D., Cochrane, C.G., and Levin, I.W. (1991). Raman-Spectroscopic Studies of Model Human Pulmonary Surfactant Systems - Phospholipid Interactions with Peptide Paradigms for the Surfactant Protein Sp-B. Biochemistry-Us 30, 8395-8401.

25. Cochrane, C.G., and Revak, S.D. (1994). Protein-Phospholipid Interactions in Pulmonary Surfactant the B-Francis-Parker-Lectureship. Chest 105, S57-S62.

26. (1998). List no. 405: New Names. Clinical Pharmacology \& Therapeutics 63, 704-706.

27. Cochrane, C.G., and Revak, S.D. (1995). Pulmonary surfactant protein and related polypeptides 
28. Revak, S.D., Merritt, T.A., Cochrane, C.G., Heldt, G.P., Alberts, M.S., Anderson, D.W., and Kheiter, A. (1996). Efficacy of synthetic peptide-containing surfactant in the treatment of respiratory distress syndrome in preterm infant rhesus monkeys. Pediatr Res 39, 715-724.

29. Cochrane, C.G., Revak, S.D., Merritt, A., Heldt, G.P., Hallman, M., Cunningham, M.D., Easa, D., Pramanik, A., Edwards, D.K., and Alberts, M.S. (1996). The efficacy and safety of KL(4)-surfactant in infants with respiratory distress syndrome. Am J Resp Crit Care 153, 404-410.

30. Cochrane, C.G., Revak, S.D., Merritt, T.A., Schraufstatter, I.U., Hoch, R.C., Henderson, C., Andersson, S., Takamori, H., and Oades, Z.G. (1998). Bronchoalveolar lavage with KL4-Surfactant in models of meconium aspiration syndrome. Pediatr Res 44, 705-715.

31. Gastiasoro-Cuesta, E., Alvarez-Diaz, F.J., Rey-Santano, C., Arnaiz-Renedo, A., Loureiro-Gonzalez, B., and Valls-i-Soler, A. (2006). Acute and sustained effects of lucinactant versus poractant-alpha on pulmonary gas exchange and mechanics in premature lambs with respiratory distress syndrome. Pediatrics 117, 295-303.

32. Rey-Santano, C., Alvarez-Diaz, F.J., Mielgo, V., Murgia, X., Lafuente, H., Ruiz-del-Yerro, E., Soler, A.V.I., and Gastiasoro, E. (2011). Bronchoalveolar Lavage versus Bolus Administration of Lucinactant, a Synthetic Surfactant in Meconium Aspiration in Newborn Lambs. Pediatr Pulm 46, 991-999.

33. Mazela, J., Merritt, T.A., Terry, M.H., Gregory, T.J., and Blood, A.B. (2012). Comparison of poractant alfa and lyophilized lucinactant in a preterm lamb model of acute respiratory distress. Pediatr Res 72, 32-37.

${ }^{*}$ A key pre-clinical study showing lucinactant can be utilized in a lyphilized form.

34. Murgia, X., Mielgo, V., Valls-i-Soler, A., Ruiz-del-Yerro, E., and Rey-Santano, C. (2012). Aerosolized perfluorocarbon improves gas exchange and pulmonary mechanics in preterm lambs with severe respiratory distress syndrome. Pediatr Res 72, 393-399.

35. Rey-Santano, C., Mielgo, V.E., Gastiasoro, E., Alvarez-Diaz, F.J., Lafuente, H., Valls-i-Soler, A., and Murgia, X. (2012). Comparative effects of bronchoalveolar lavage with saline, surfactant, or perfluorocarbon in experimental meconium aspiration syndrome. Pediatr Crit Care Me 13, E187-E194.

36. Wolfson, M.R., Wu, J.C., Hubert, T.L., Gregory, T.J., Mazela, J., and Shaffer, T.H. (2012). Lucinactant attenuates pulmonary inflammatory response, preserves lung structure, and improves physiologic outcomes in a preterm lamb model of RDS. Pediatr Res 72, 375-383.

37. Moya, F.R., Gadzinowski, J., Bancalari, E., Salinas, V., Kopelman, B., Bancalari, A., Kornacka, M.K., Merritt, T.A., Segal, R., Schaber, C.J., et al. (2005). A multicenter, randomized, masked, comparison trial of lucinactant, colfosceril palmitate, and beractant for the prevention of respiratory distress syndrome among very preterm infants. Pediatrics 115, 1018-1029.

${ }^{* *}$ One of two clinical trials leading to FDA approval of lucinactant

38. Moya, F., Sinha, S., Gadzinowski, J., D'Agostino, R., Segal, R., Guardia, C., Mazela, J., Liu, G., SELECT, and Investigators, S.S. (2007). One-year follow-up of very preterm infants who received lucinactant for prevention of respiratory distress syndrome: Results from 2 multicenter randomized, controlled trials. Pediatrics 119, E1361-E1370.

39. Sinha, S.K., Lacaze-Masmonteil, T., Soler, A.V.I., Wiswell, T.E., Gadzinowski, J., Hajdu, J., Bernstein, G., d'Agostino, R., and Dist, S.T.A.R. (2005). A multicenter, randomized, controlled trial of lucinactant versus poractant alfa among very premature infants at high risk for respiratory distress syndrome. Pediatrics 115, 1030-1038.

${ }^{* *}$ The second clinical trial leading to FDA approval of lucinactant

40. Wiswell, T.E., Knight, G.R., Finer, N.N., Donn, S.M., Desai, H., Walsh, W.F., Sekar, K.C., Bernstein, G., Keszler, M., Visser, V.E., et al. (2002). A multicenter, randomized, controlled trial comparing surfaxin (lucinactant) lavage with standard care for treatment of meconium aspiration syndrome. Pediatrics 109, $1081-1087$.

41. Wiswell, T.E., Smith, R.M., Katz, L.B., Mastroianni, L., Wong, D.Y., Willms, D., Heard, S., Wilson, M., Hite, R.D., Anzueto, A., et al. (1999). Bronchopulmonary segmental lavage with surfaxin (KL4surfactant) for acute respiratory distress syndrome. Am J Resp Crit Care 160, 1188-1195.

42. Thomas, N.J., Guardia, C.G., Moya, F.R., Cheifetz, I.M., Markovitz, B., Cruces, P., Barton, P., Segal, R., Simmons, P., Randolph, A.G., et al. (2012). A pilot, randomized, controlled clinical trial of 
lucinactant, a peptide-containing synthetic surfactant, in infants with acute hypoxemic respiratory failure. Pediatr Crit Care Me 13, 646-653.

43. Kinniry, P., Pick, J., Stephens, S., Jain, D., Solomides, C.C., Niven, R., Segal, R., and ChristofidouSolomidou, M. (2006). KL4-surfactant prevents hyperoxic and LPS-induced lung injury in mice. Pediatr Pulm 41, 916-928.

44. Romero, E.J., Moya, F.R., Tuvim, M.J., and Alcorn, J.L. (2005). Interaction of an artificial surfactant in human pulmonary epithelial cells. Pediatr Pulm 39, 167-177.

*This study shows the uptake of lucinactant into epithelial cells suggesting it might be utilized as a drug delivery vehicle

45. Piehl, E., and Fernandez-Bustamante, A. (2012). Lucinactant for the Treatment of Respiratory Distress Syndrome in Neonates. Drug Today 48, 587-593.

46. Ardell, S., Pfister, R.H., and Soll, R. (2015). Animal derived surfactant extract versus protein free synthetic surfactant for the prevention and treatment of respiratory distress syndrome. Cochrane $\mathrm{Db}$ Syst Rev.

47. Manalo, E., Merritt, T.A., Kheiter, A., Amirkhanian, J., and Cochrane, C. (1996). Comparative effects of some serum components and proteolytic products of fibrinogen on surface tension-lowering abilities of beractant and a synthetic peptide containing surfactant KL(4)(1). Pediatr Res 39, 947-952.

${ }^{*} \mathrm{~A}$ key paper showing lucinactant is more robust than animal-derived PS

48. Jordan, B.K., and Donn, S.M. (2013). Lucinactant for the prevention of respiratory distress syndrome in premature infants. Expert Rev Clin Phar 6, 115-121.

49. Johansson, J., and Curstedt, T. (1997). Molecular structures and interactions of pulmonary surfactant components. Eur J Biochem 244, 675-693.

50. Munford, R.S., Sheppard, P.O., and O'Hara, P.J. (1995). Saposin-like proteins (SAPLIP) carry out diverse functions on a common backbone structure. J Lipid Res 36, 1653-1663.

51. Vandenbussche, G., Clercx, A., Clercx, M., Curstedt, T., Johansson, J., Jornvall, H., and Ruysschaert, J.M. (1992). Secondary Structure and Orientation of the Surfactant Protein Sp-B in a Lipid Environment - a Fourier-Transform Infrared-Spectroscopy Study. Biochemistry-Us 31, 9169-9176.

52. Gustafsson, M., Vandenbussche, G., Curstedt, T., Ruysschaert, J.M., and Johansson, J. (1996). The 21-residue surfactant peptide (LysLeu4)4Lys $(K L 4)$ is a transmembrane alpha-helix with a mixed nonpolar/polar surface. FEBS Lett 384, 185-188.

53. Cai, P., Flach, C.R., and Mendelsohn, R. (2003). An infrared reflection-absorption spectroscopy study of the secondary structure in (KL4)4K, a therapeutic agent for respiratory distress syndrome, in aqueous monolayers with phospholipids. Biochemistry-Us 42, 9446-9452.

54. Mills, F.D., Antharam, V.C., Ganesh, O.K., Elliott, D.W., McNeill, S.A., and Long, J.R. (2008). The helical structure of surfactant peptide $\mathrm{KL}(4)$ when bound to POPC : POPG lipid vesicles. BiochemistryUs 47, 8292-8300.

55. Antharam, V.C., Elliott, D.W., Mills, F.D., Farver, R.S., Sternin, E., and Long, J.R. (2009). Penetration Depth of Surfactant Peptide KL4 into Membranes Is Determined by Fatty Acid Saturation. Biophys J 96, 4085-4098.

*The first study demonstrating the differential partitioning of $\mathrm{KL}_{4}$ into lipid environments of varying fatty acid saturation

56. Ma, J.W., Koppenol, S., Yu, H.U., and Zografi, G. (1998). Effects of a cationic and hydrophobic peptide, $\mathrm{KL} 4$, on model lung surfactant lipid monolayers. Biophys J 74, 1899-1907.

57. Martinez-Gil, L., Perez-Gil, J., and Mingarro, I. (2008). The surfactant peptide KL4 sequence is inserted with a transmembrane orientation into the endoplasmic reticulum membrane. Biophys J 95, L36-L38.

58. Saenz, A., Canadas, O., Bagatolli, L.A., Johnson, M.E., and Casals, C. (2006). Physical properties and surface activity of surfactant-like membranes containing the cationic and hydrophobic peptide KL4.

Febs J 273, 2515-2527.

59. Nord, E.P., Brown, S.E.S., and Crandall, E.D. (1988). Cl-/Hco-3 Exchange Modulates Intracellular Ph in Rat Type-li Alveolar Epithelial-Cells. J Biol Chem 263, 5599-5606.

60. Effros, R.M., and Chinard, F.P. (1969). In Vivo Ph of Extravascular Space of Lung. J Clin Invest 48, 1983-\&. 
61. Turner, A.L., Braide, O., Mills, F.D., Fanucci, G.E., and Long, J.R. (2014). Residue specific partitioning of KL4 into phospholipid bilayers. Bba-Biomembranes 1838, 3212-3219.

62. Long, J.R., Mills, F.D., Ganesh, O.K., Antharam, V.C., and Farver, R.S. (2010). Partitioning, dynamics, and orientation of lung surfactant peptide KL4 in phospholipid bilayers. Bba-Biomembranes 1798, 216222.

63. Schrodinger, LLC (2015). The PyMOL Molecular Graphics System, Version 1.8.

64. Wu, E.L., Cheng, X., Jo, S., Rui, H., Song, K.C., Davila-Contreras, E.M., Qi, Y.F., Lee, J.M., MonjeGalvan, V., Venable, R.M., et al. (2014). CHARMM-GUI Membrane Builder Toward Realistic Biological Membrane Simulations. J Comput Chem 35, 1997-2004.

65. Antharam, V.C., Farver, R.S., Kuznetsova, A., Sippel, K.H., Mills, F.D., Elliott, D.W., Sternin, E., and Long, J.R. (2008). Interactions of the C-terminus of lung surfactant protein B with lipid bilayers are modulated by acyl chain saturation. Bba-Biomembranes 1778, 2544-2554.

66. Booth, V., Waring, A.J., Walther, F.J., and Keough, K.M.W. (2004). NMR structures of the C-terminal segment of surfactant protein B in detergent micelles and hexafluoro-2-propanol. Biochemistry-Us 43, 15187-15194.

67. Farver, R.S., Mills, F.D., Antharam, V.C., Chebukati, J.N., Fanucci, G.E., and Long, J.R. (2010). Lipid Polymorphism Induced by Surfactant Peptide SP-B1-25. Biophys J 99, 1773-1782.

68. Farver, S., Smith, A.N., Mills, F.D., Egri, A.G., and Long, J.R. (2015). Delineation of the dynamic properties of individual lipid species in native and synthetic pulmonary surfactants. Bba-Biomembranes 1848, 203-210.

69. Waring, A.J., Walther, F.J., Gordon, L.M., Hernandez-Juviel, J.M., Hong, T., Sherman, M.A., Alonso, C., Alig, T., Braun, A., Bacon, D., et al. (2005). The role of charged amphipathic helices in the structure and function of surfactant protein B. J Pept Res 66, 364-374.

*The first study of a chimeric construct of the $\mathrm{N}$ - and $\mathrm{C}$-termini of SP-B demonstrating superior funcion

70. Sarker, M., Waring, A.J., Walther, F.J., Keough, K.M.W., and Booth, V. (2007). Structure of mini-B, a functional fragment of surfactant protein B, in detergent micelles. Biochemistry-Us 46, 11047-11056. 